\title{
Femur distal kırıklarının intramedüller çivi ile tedavisinde karşılaşılabilecek sorunlar ve çözüm yöntemleri
}

\section{Problems and solution methods in treatment of distal fractures of the femur with intramedullary nails}

\author{
Mustafa Seyhan
}

Acıbadem Üniversitesi, Acıbadem Altunizade Hastanesi, İstanbul

\begin{abstract}
Femur distal kırıkları genellikle gençlerde yüksek, yaşlılarda düşük enerjili travmalar sonucu meydana gelir. Ekleme uzanan kırıklarda, iki yönlü röntgen ile birlikte bilgisayarlı tomografi çektirmekte yarar vardır. Femur distal kırıklarında gastroknemius adalesi sagittal düzlemde rekurvatuma, kuadriseps adalesi ise kısalığa yol açar. Redüksiyon manevraları ve tedavi süreci bu deformiteleri düzeltmeye yönelik olmalıdır. Kilitli plaklar dışında, intramedüller çivileme biyomekanik avantajları nedeniyle tercih edilen iyi bir tedavi alternatifidir. Eklem dışı distal femur kırıkları ile interkondiler tek kırık hattının olduğu kısmi eklem kırıklarında kurallarına uygun biçimde uygulanmış retrograd intramedüller çivileme ile son derece başarılı sonuçlar alınmaktadır. Ameliyat supin pozisyonda, diz altına radyolüsen yükselti konarak, mediyal artrotomi ile yapılır. Ameliyatta en önemli potansiyel problem redüksiyon problemidir. ilk olarak elle traksiyon yapılarak uzunluk sağlanmaya ve diz altına konan yükseltiden yararlanarak rekurvatum düzeltilmeye çalışılır. Redüksiyon sağlanamıyorsa deformitenin gerektirdiği şekilde ucu topuzlu itici, redüksiyon klempi, femur distraktörü, distal parçanın anteriorundan iskelet traksiyonu veya deplasman yönünün ters tarafından bloklama vidası kullanılabilir. Ameliyat baştan sona skopi kontrolünde yapılır. Doğru giriş noktası seçilmeli, uygun uzunluk ve kalınlıktaki çivi uygulanmalı, kullanılacak çivi son oyucudan 1,0 veya 1,5 $\mathrm{mm}$ düşük çapta olmalı, çivi eklem içine taşar durumda bırakılmamalıdır. Distal kilitleme eksternal yönlendiricilerle, proksimal kilitleme serbest el tekniği ile daha çok ön-arka yönde yapılır. Özellikle osteoporotik kırıklarda spiral kamalı tasarım, birden fazla düzlemde sağladığı güçlü stabilite nedeniyle tercih edilmektedir. Uzunluk ve rotasyon, sağlam tarafla karşılaştırılarak ayarlanmalıdır. Ameliyat bitiminde belirgin bir uzunluk veya rotasyon farkı saptanırsa proksimal kilit vidalarının yeri değiştirilerek sorun düzeltilmelidir.
\end{abstract}

Anahtar sözcükler: femur distal kırığı retrograd çivileme; femur distal kırı̆ı intramedüller çivileme; femur distal kırı̆̆ı
Generally, distal femoral fractures are due to high-energy trauma in young people but low-energy trauma in elderly. In the fractures that extend into the knee joint, it is useful to take computed tomography in addition to double-sided $X$-ray. In distal fractures of femur, gastrocnemius causes recurvatum and quadriceps causes shortness. Reduction maneuvers and treatment procedure should be planned for correcting these deformities. Putting aside locking plates, intramedullary nailing is a good alternative treatment option for its biomechanical advantages. In extraarticular distal femur fractures and partial intraarticular fractures with a single intercondylar fracture line, excellent results are achieved with appropriately performed retrograde intramedullary nailing. Operation is performed in supine position with medial arthrotomy with a radiolucent elevator put below the knee. The most important potential problem in surgery is reduction. First of all, manual traction is used to avoid shortness, and an elevator below the knee is used to correct recurvatum. If reduction fails, as deformity requires, ball spike pusher, reduction clamp, femoral distractor, skeletal traction from anterior side of distal fragment, and blocking screw from the opposite direction of displacement can be used. Operation is performed with scope from beginning to end. The right entering spot should be chosen, nail length and thickness should be appropriate. Diameter of the nail should be 1.0 or $1.5 \mathrm{~mm}$ thinner than the largest drill used. Nail shouldn't extend into the knee joint. Distal locking is done with external guides, and proximal locking is done with freehand techniques, more often in anterior-posterior direction. Especially in osteoporotic fractures, spiral blade design is preferred because it provides strong multiplanar stability. Length and rotation should be adjusted by comparing with the healthy side. If an obvious difference in length and rotation is observed after the surgery, the problem should be solved by replacing proximal locking screws.

Key words: retrograde nailing of distal femoral fracture; intramedullary nailing of distal femoral fracture; distal femur fracture

- Illetişim adresi: Doç. Dr. Mustafa Seyhan, Altunizade mah. Tophanelioğlu cad. Okul sok. No: 1, Üsküdar, İstanbul Tel: 0216 - 6494240 e-posta: mustafa.seyhan@acibadem.com

- Geliş tarihi: 1 Eylül 2018 Kabul tarihi: 1 Eylül 2018 
emur distal kırıkları genellikle gençlerde yüksek enerjili, yaşlılarda düşük enerjili travmalar sonucu meydana gelir. Özellikle yüksek enerjili travmalarda, eşlik eden başka yaralanmalar olabileceği akıldan çıkarılmamalıdır. Aynı taraf femur proksimal bölge kırıklarını gözden kaçırmamak için, iki yönlü röntgen incelemesi bütün femuru gösterecek şekilde yapılmalıdır. Röntgenle, interkondiler kırıkların iyi değerlendirilmesi ve koronal düzlemdeki Hoffa kırığının fark edilmesi mümkün olmayabilir. İntramedüller çivileme için kontrendikasyon teşkil edebilecek bu durumların önüne geçmek için, ekleme uzanan femur distal kırıklarında rutin olarak bilgisayarlı tomografı çektirmekte yarar vardır. ${ }^{[1-3]}$

\section{ANATOMI}

Distal femur, istmustan sonra distale doğru trapezoid bir şekil alarak genişler. Çivinin intramedüller kanalı diyafiz bölgesindeki kadar destekleyemeyecek olması kaliteli redüksiyon elde edilememesine, dolayısıyla malunion veya nonuniona yol açabilmektedir. Distal kırık segmenti kısaldıkça malunion riski aynı oranda artar. ${ }^{[4,5]}$

Distal femura yapışan gastroknemius adalesi başlıca deforme edici etmendir ve kırığın sagittal düzlemde rekurvatuma yönelmesine neden olur. Kuadriseps adalesinin etkisi kısalığa yol açar. Ayrıca adduktor adalelerin etkisiyle varus, kırı̆ın morfolojisine göre bazen de valgus deformitesi oluşabilir (Şekil 1).

\section{CERRAHI TEDAVI}

Distal femur kırığı tedavisinde, kilitli plaklar ile minimal invaziv veya açık plak osteosentezi seçkin tedavi yöntemleridir. Dinamik kondiler çivili plak veya sabit açılı plak da kullanılabilmekte; intramedüller çivi ise uygun kırıklarda biyomekanik avantajı nedeniyle tercih edilebilmektedir. ${ }^{[6-8]}$ Distale yakın kırıkların intramedüller çivilenmesinde en önemli potansiyel problem redüksiyon yetersizliği ve maluniondur. Yardımcı redüksiyon yöntemleri kullanarak bu sorunun etkin bir şekilde çözümü halinde, intramedüller çivilemenin distal femur kırıklarında daha sık kullanılması mümkün olacaktır. Distal femur diyafiz kırıklarında antegrad intramedüller çivileme de yapılabilmekle birlikte, daha distaldeki kırıklarda retrograd çivileme tercih edilmektedir. ${ }^{[4,9-12]}$

Femur distal kırıklarının AO (Arbeitsgemeinschaft für Osteosynthesefragen) sınıflamasına göre kısmi eklem kırıkları (B1, B2, B3) ile kompleks eklem içi kırıklar (C3) retrograd intramedüller çivilemeye uygun değildir (Şekil 2). A tipi kırıklar retrograd çivileme için idealdir. Interkondiler tek kırık hattının olduğu $C 1$ ve $C 2$ tipi

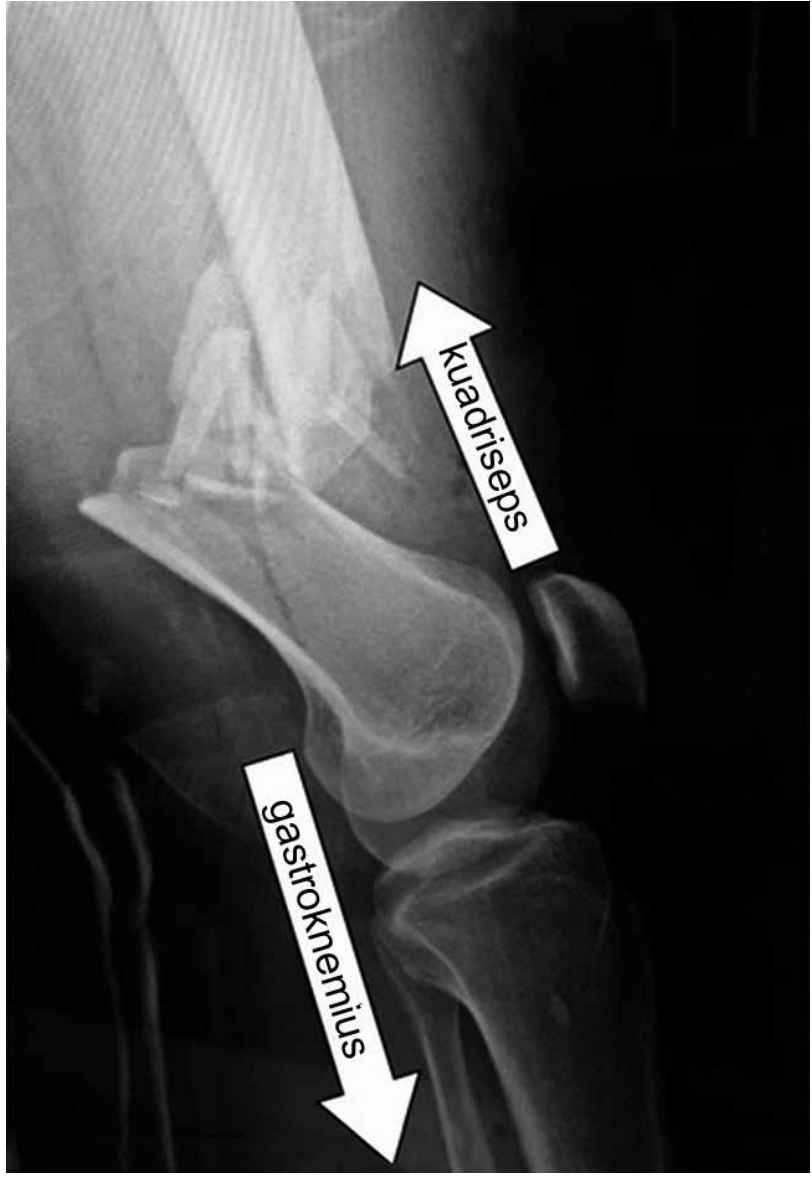

Şekil 1. Distal femura yapışan gastroknemius adalesi kırı̆̆ın sagittal düzlemde rekurvatuma yönelmesine kuadriseps adalesi ise kısalığa neden olur.

kısmi eklem kırıklarında ise, eklemin anatomik redüksiyonu ve çivi yolunu engellemeyen çift korteks iki lag vidası uygulaması sonrası retrograd çivileme yapılabilir (Şekil 3). ${ }^{[13,14]}$

\section{Retrograd İntramedüller Çivileme}

Retrograd çivileme AO B1, B2, B3 ve C3 dışında kalan distal femur kırıkları yanında tüm femur cisim kırıklarına da uygulanabilmektedir. Obezlerde cerrahiyi kolaylaştırmak, gebelerde fetüsün maruz kalacağı radyasyon miktarını azaltmak, bilateral femur kırıklarında ve yüzen dizde hasta hazırlığı ve cerrahi işlemleri kolaylaştırmak açısından, retrograd çivileme avantaj sağlamaktadır. Femur kırığı ile birlikte asetabulum veya pelvis kırığı varlığında aynı bölgeye birbirine engel insizyonlar yapmamak, aynı taraf kalça kırığı varlığında kalça kırığı için daha ideal implant seçimi yapabilmek, instabil spinal yaralanması da olan hastalarda ilave spinal yaralanma riskini azaltmak için, retrograd çivileme tercih edilebilir. ${ }^{[15,16]}$ 


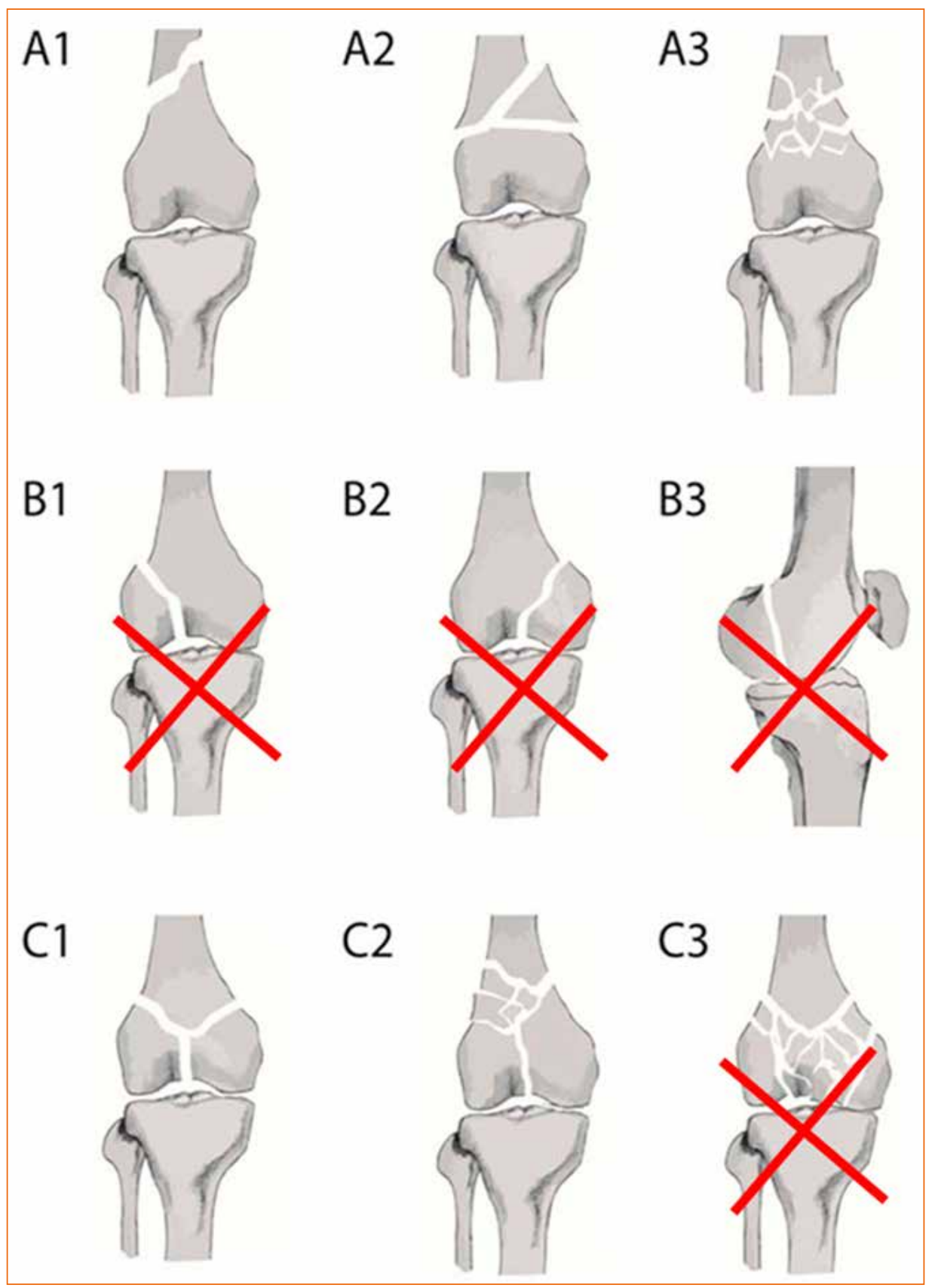

Şekil 2. Femur distal kırıklarının AO sınıflamasına göre kısmi eklem kırıkları (B1, B2, B3) ile kompleks eklem içi kırıklar (C3) retrograd intramedüller çivilemeye uygun değildir.

Dizde aktif enfeksiyon veya kontamine yara varlığı ile diz fleksiyonunda kısıtlılık ve iskelet gelişiminin tamamlanmamış olması retrograd çivileme için kontrendikasyonlardır. Retrograd çivileme komplikasyonları olarak ise; diz önü ağrısı, dizde kısıtlııı, dizilim bozukluğu, çivinin eklem içine taşması, enfeksiyon ve diz septik artrit riski sayılabilir. ${ }^{[14,16]}$

\section{Ameliyat Öncesi Planlama ve Çivi Seçimi}

Kırık tipinin retrograd çivilemeye uygun olması yanında, femur şaft eğimlerinin de çivilemeye engel teşkil etmemesi gerekir. İki yönlü röntgen görüntülerinden femur kanalının en dar yerinin çapı çivi genişliği olarak belirlense de, nihai karar ameliyat esnasında oyma işlemi sırasında verilir. 

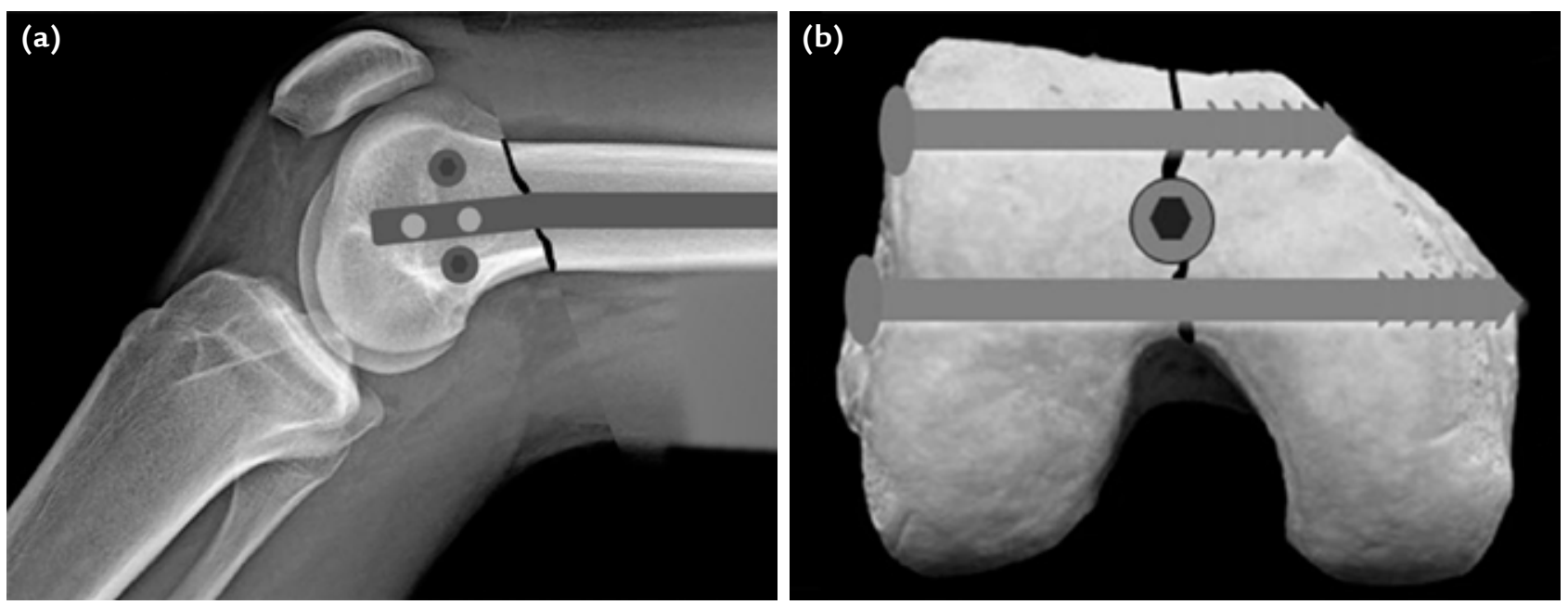

Şekil 3. a, b. Interkondiler tek kırık hattının olduğu AO C1 ve C2 tip kırıklarda eklemin anatomik redüksiyonu ve çivi yolunu engellemeyen iki lag vidası uygulaması sonrası retrograd çivileme yapılabilir.

Distal femur kırığı için kısa ve tam uzunlukta çivi tasarımları olmakla birlikte, artık daha çok trokanter minör seviyesine kadar uzanan uzun çiviler tercih edilmektedir. Ameliyatta kullanılacak retrograd çivinin uzunluk ve kalınlık opsiyonları ile beraber distal kilit vida deliklerinin düzlemleri ve çivi ucuna olan mesafeleri biliniyor olmalıdır. Güçlü tutunum sağlayan spiral kamalı tasarımlar özellikle osteoporotik hastalarda sık tercih edilir olmuştur. ${ }^{[8]}$

Ameliyata başlamadan ve steril hazırlık yapılmadan önce, hasta supin pozisyonda iken sağlam taraftan uzunluk ve rotasyon ölçümü yapılmalıdır. Femurun üst ve alt uçları skopi ile görüntülenip işaretlenerek femur uzunluğu ölçülebilir. Çivi sistemi ile kalibre edilmiş cetvel mevcut ise, troklear çentik tepe noktası ile trokanter minör üst seviyesi arası ölçülüp çivi uzunluğu belirlenebilir. Ameliyatta bu uzunluktaki çivi kullanıldığı ve başlangıç ile sonlanma noktalarına sadık kalındığı takdirde uzunluk eşitlenmiş olur. Rotasyon ölçümü için, sağlam taraf kalça ve diz fleksiyona alınarak iç ve dış rotasyon açılarına bakılmalıdır. ${ }^{[14]}$ Ayrıca, spina iliaka anterior superior ve patella ortasından distale uzatılan kablonun hangi parmak hizasından geçtiğine bakılarak rotasyon karşılaştırması yapılabilir.

\section{Hasta Pozisyonu}

Hasta supin pozisyonda, femurun altı tamamen boş bir radyolüsen masaya yatırılır. Skopi karşı tarafa alınır ve tüm femurun iki yönlü görüntülemesini sağlayabilecek şekilde konumlandırılır. Ekstremite iliak kanattan ayak bileğine kadar steril hazırlanır. Ameliyat esnasında dizi hafif fleksiyonda tutmak ve tam yan görüntüleme alabilmek için, diz altına radyolüsen yükseltici veya rulo yapılmış havlu yerleştirilir.

\section{Giriş}

Mediyal paratendinöz artrotomi yapılır. Giriş deliği için kılavuz telin giriş noktası, lateral görüntülemede Blumensaat çizgisinin distal tepe noktası, ön-arka görüntülemede troklear oluğun ortası veya hafif mediyalinde femur şaft aksında olmalıdır (Şekil 4). Arka çapraz bağ yapışma yerinin hemen önü olan bu noktadan kılavuz tel sokulurken, bağın yapışma yerine girmemek için cerrah elini hafifçe aşağı indirmeli, korteksi geçtikten sonra tekrar elini kaldırıp femur aksında ilerlemelidir. Daha sonra, giriş deliği kanüllü oyucu ile genişletilir. Genişletilmiş giriş deliğinden sokulan topuzlu kılavuz tel, yönlendirici yardımıyla skopi kontrolünde kırık bölgesinden geçirilip medulladan femur proksimaline kadar ilerletilir. ${ }^{[14]}$

\section{Kırık Redüksiyonu}

Anestezi verilip kas gevşemesi sağlandıktan sonra, ilk olarak elle traksiyon yapılarak uzunluk sağlanmaya çalışılır. Distal femura yapışan gastroknemius adalesinin etkisiyle, kırık çoğu zaman sagittal düzlemde rekurvatuma yönelmiş durumdadır. Rekurvatum açılanmasını düzeltmek için diz altına yastık veya rulo havlu yerleştirmek çoğunlukla işe yarar. Kırığın seviyesine göre diz altı desteğinin yeri değiştirilir. Başka yönde deplase parçaların redüksiyonu için ucu topuzlu iticiler veya redüksiyon klempleri kullanılabilir (Şekil 5). 

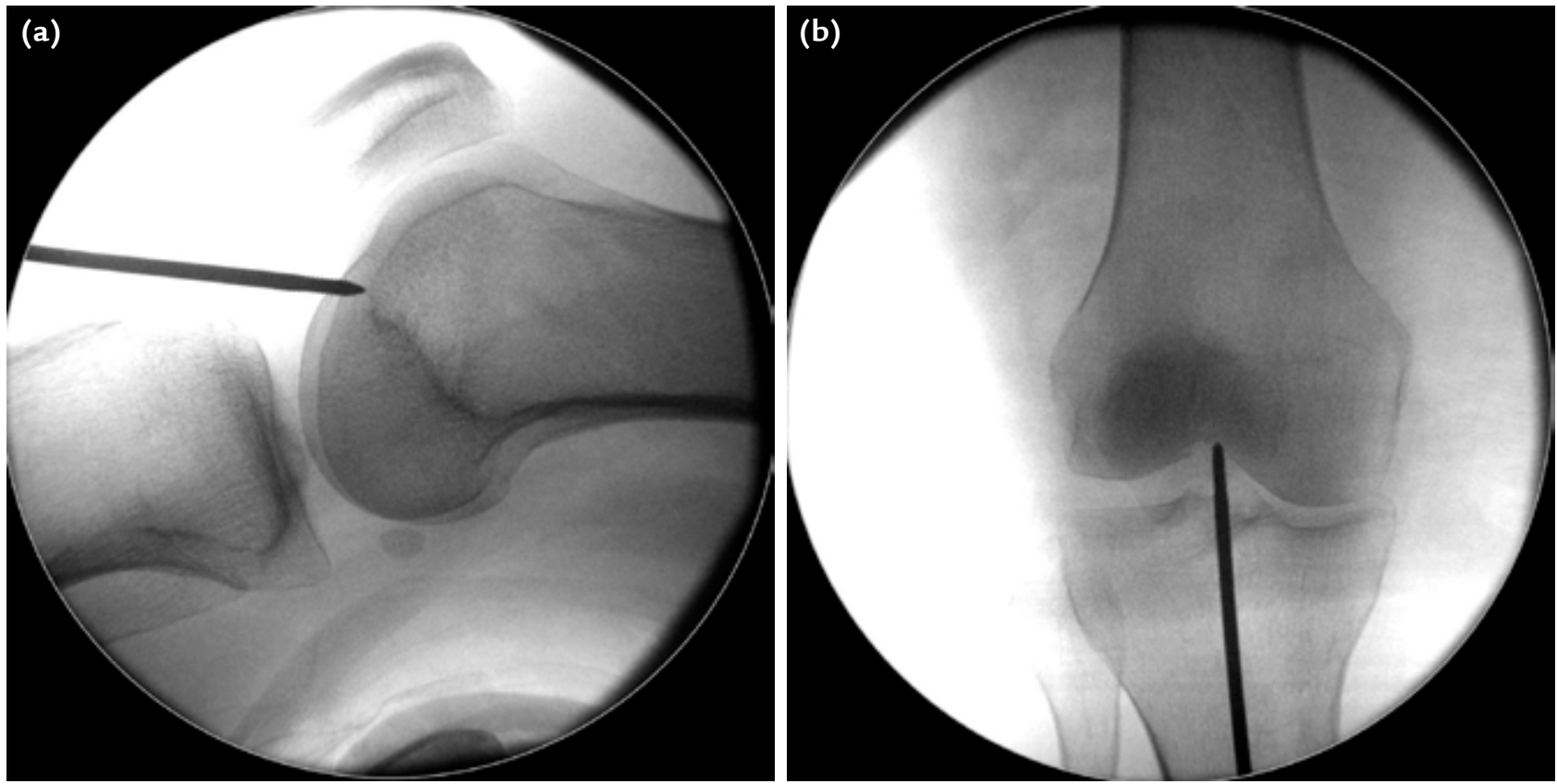

Şekil 4. a, b. Giriş noktası lateral görüntülemede Blumensaat çizgisinin tepe noktası (a), ön-arka görüntülemede troklear oluğun ortası veya hafif mediyalinde femur şaft aksındadır (b).

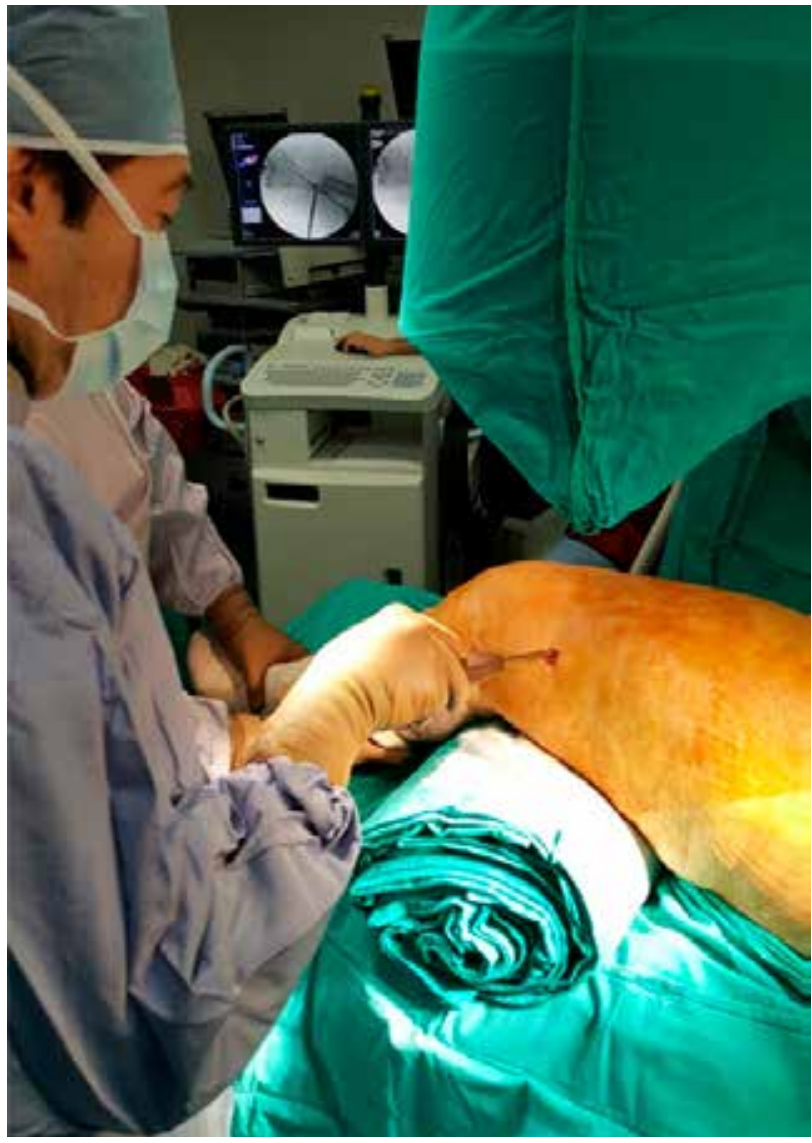

Şekil 5. Rekurvatum açılanmasını düzeltmek için diz altına çamaşır rulosu yerleştirilmiş. Laterale olan deplasman perkütan uygulanan topuzlu itici ile skopi kontrolünde redükte edilirken bir yandan da manuel traksiyon yapılıyor.
Rekurvatum açılanmasını gidermenin bir başka yolu, distal parçanın anteriorundan çivi yolunu engellemeyecek şekilde geçilen Steinmann teliyle traksiyon yapmaktır. Merkezin anteriorundan yapılan traksiyonla, ters yöne olan deplasman giderilmeye çalışılır (Şekil 6). ${ }^{[13]}$

Parçalı ve redüksiyonu güç kırıklarda femur distraktörü kullanılabilir. Lateral taraftan yerleştirilen distraktörün proksimal çivisi trokanterik bölgeye, distal çivisi ise intramedüller çivi geçişine engel olmayacak şekilde, femur distali anterior veya kondillerin posterior kısmına yahut kırık bunlara izin vermiyorsa tibia proksimaline takılır.

Bir başka yardımcı redüksiyon yönteminde, bloklama vidası intramedüller çiviyi geniş intramedüller kanalda istenen tarafa yönlendirerek redüksiyonu sağlar. Bloklama vidası, daha kısa ve geniş olan distal femur parçasına, deplasman yönünün karşı tarafına ve kırık hattına yakın ama ilave kırığa neden olmayacak makul bir mesafeye uygulanır. Sıklıkla olduğu gibi distal parça posteriora yönelmiş ise, bloklama vidasının uygulama yeri anterior korteks ile çivi arasında kırık hattına yakın bir noktadır (Şekil 7 ve 8). ${ }^{[4,9,12,17,18]}$

\section{Oyma İşlemi ve Çivinin Yerleştirilmesi}

Sekiz veya $9 \mathrm{~mm}$ oyucu ile başlanır ve $0,5 \mathrm{~mm}$ arttırılarak devam edilir. Isı nekrozundan kaçınmak için motor düşük devirde çalıştırılır. Korteksten tıkırtılı ses alınmaya başlanana kadar oymaya devam edilir. 


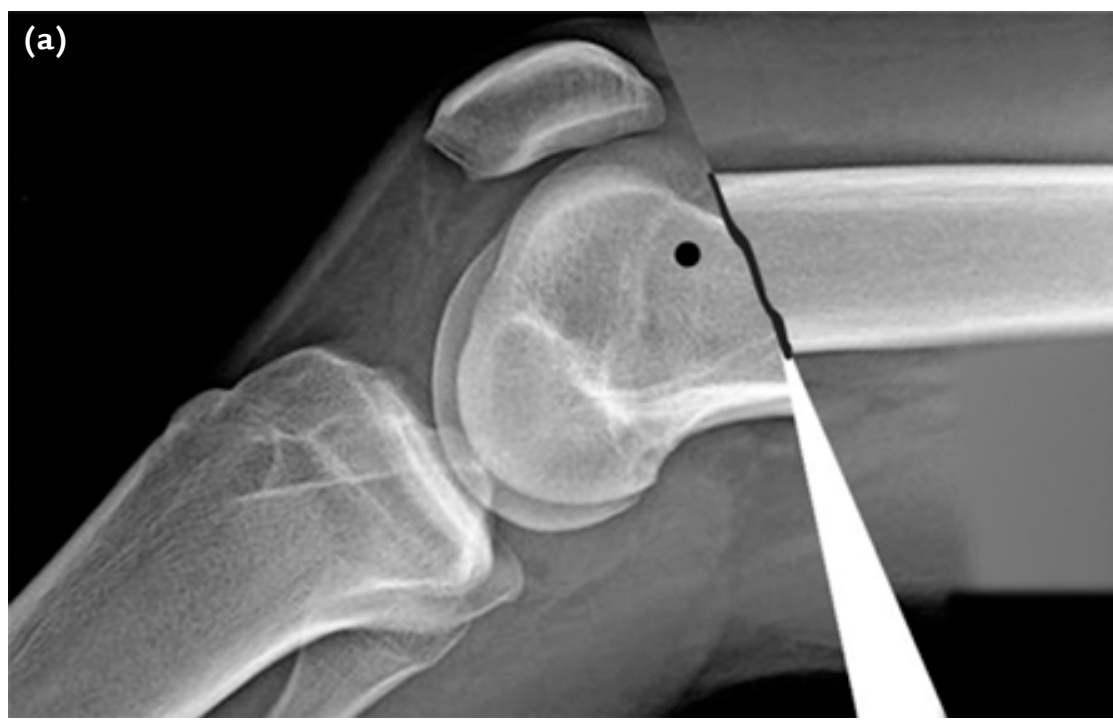

Şekil 6. a-c. Rekurvatumu gidermek için distal parçanın anteriorundan çivi yolunu engellemeyecek şekilde bir Steinmann teli takılır (a). Merkezin anteriorundan yapılan bu traksiyonla posteriora olan deplasman giderildikten sonra intramedüller çivileme yapılır $(b, c)$.
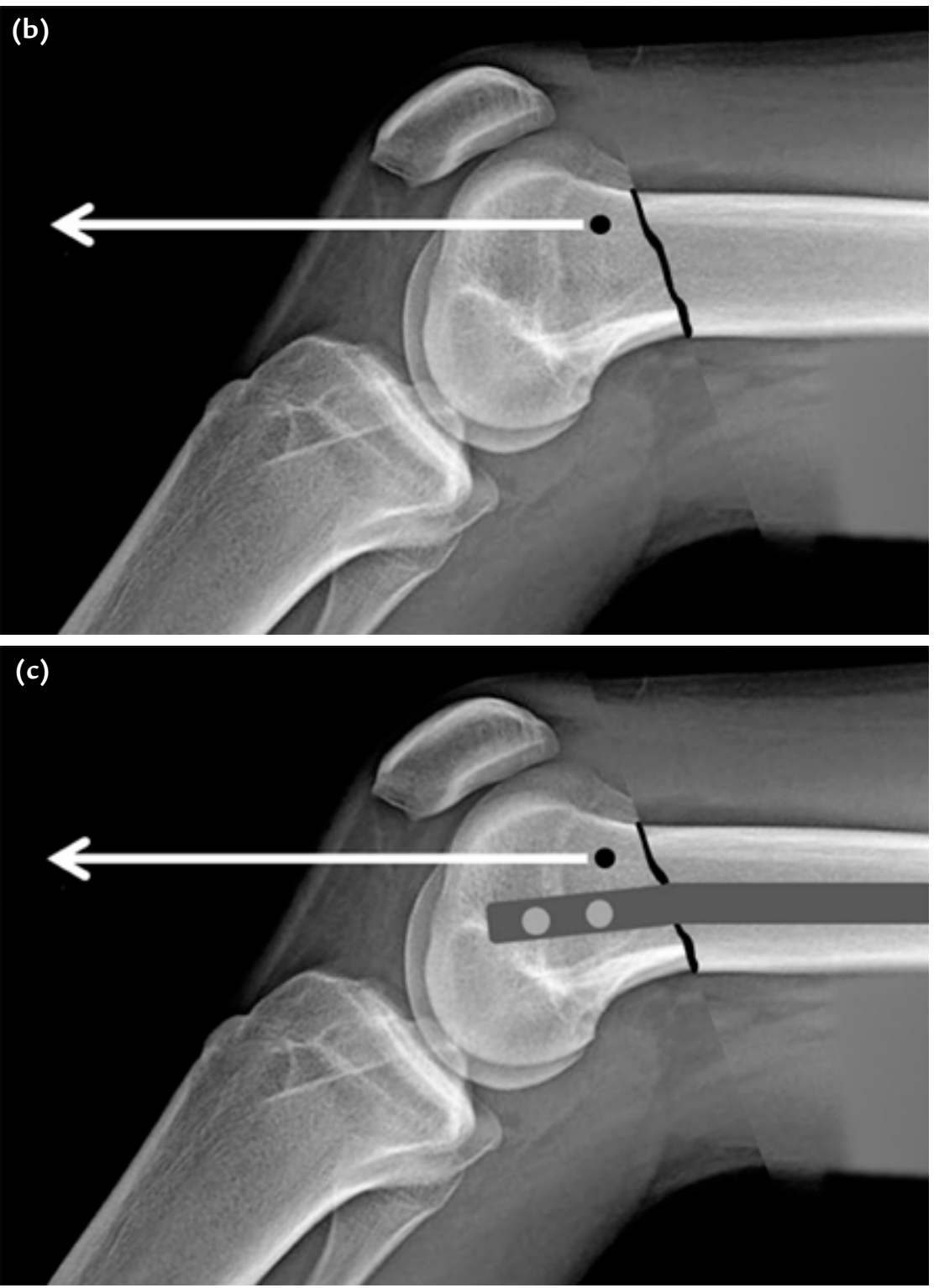

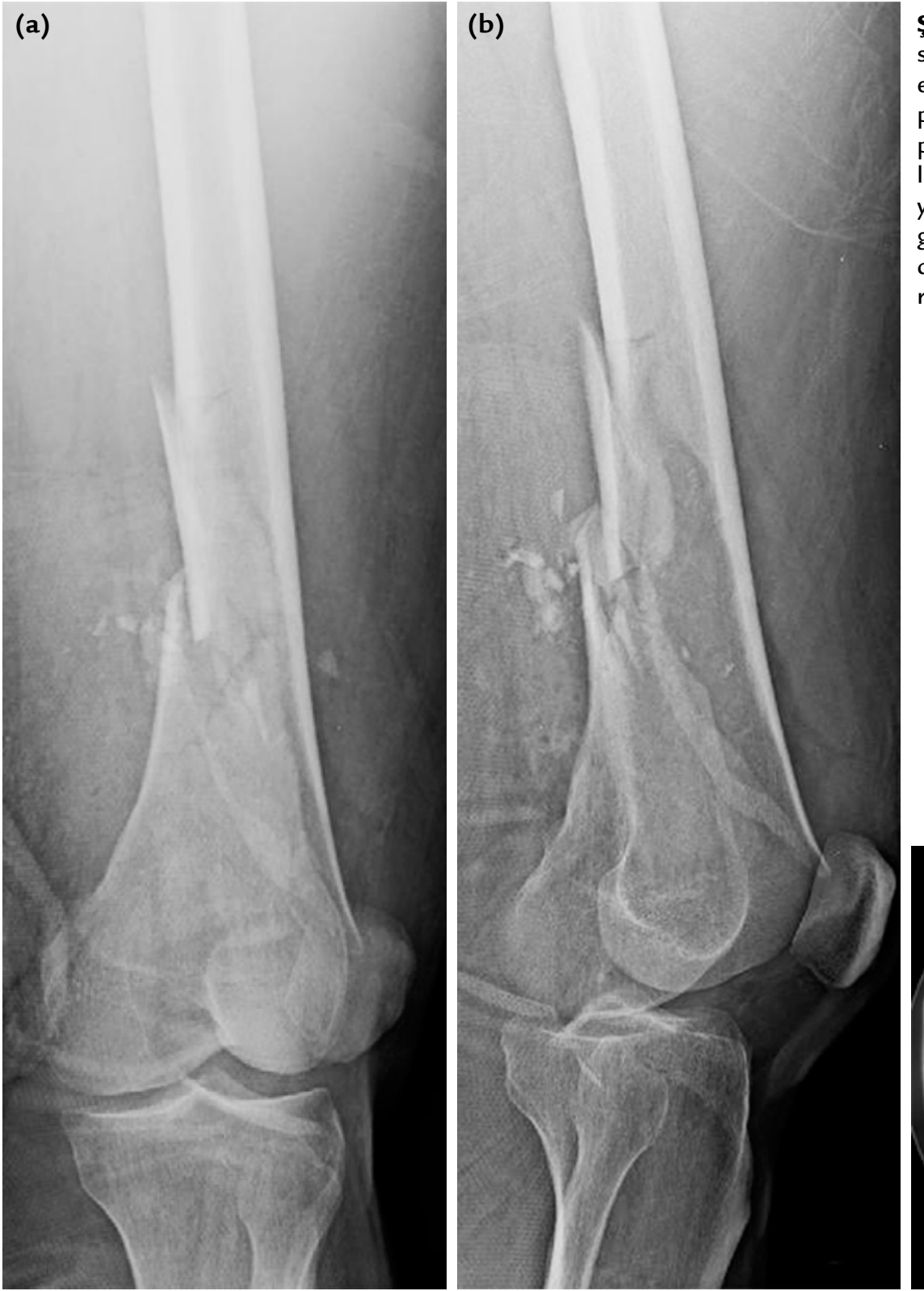

Şekil 7. a-f. Ateşli silah yaralanması sonucu femur distal kırığı (a, b). Ameliyat esnasındaki skopi görüntülerinde posteriora deplasman gösteren distal parçada kılavuz telin anterior tarafına lateralden mediyale doğru bloklama vidası yerleştiriliyor (c, d). İntramedüller çivi gönderilirken bloklama vidası posteriora deplase distal parçayı anteriora yönelterek redükte ediyor $(\mathbf{e}, \mathbf{f})$.
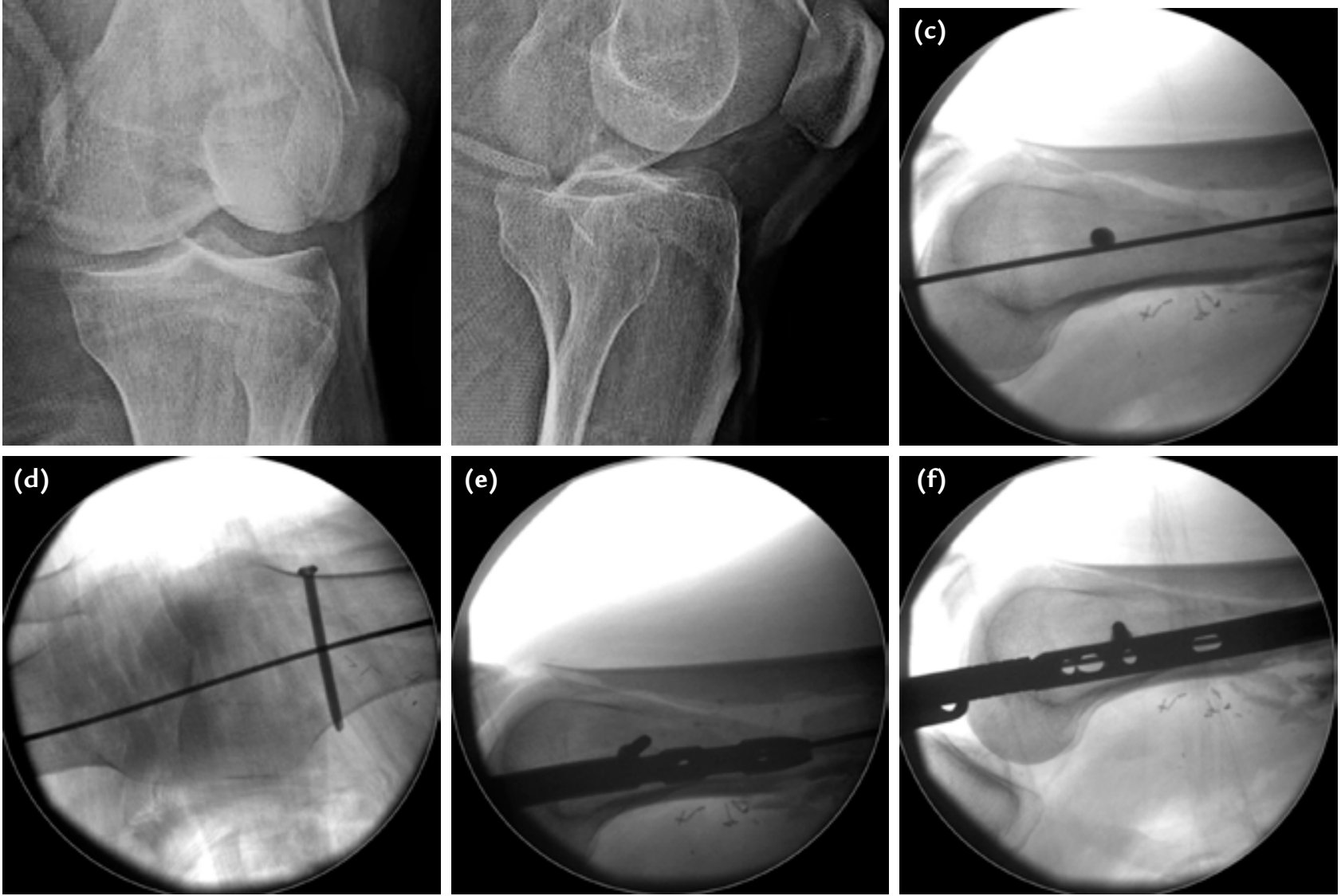

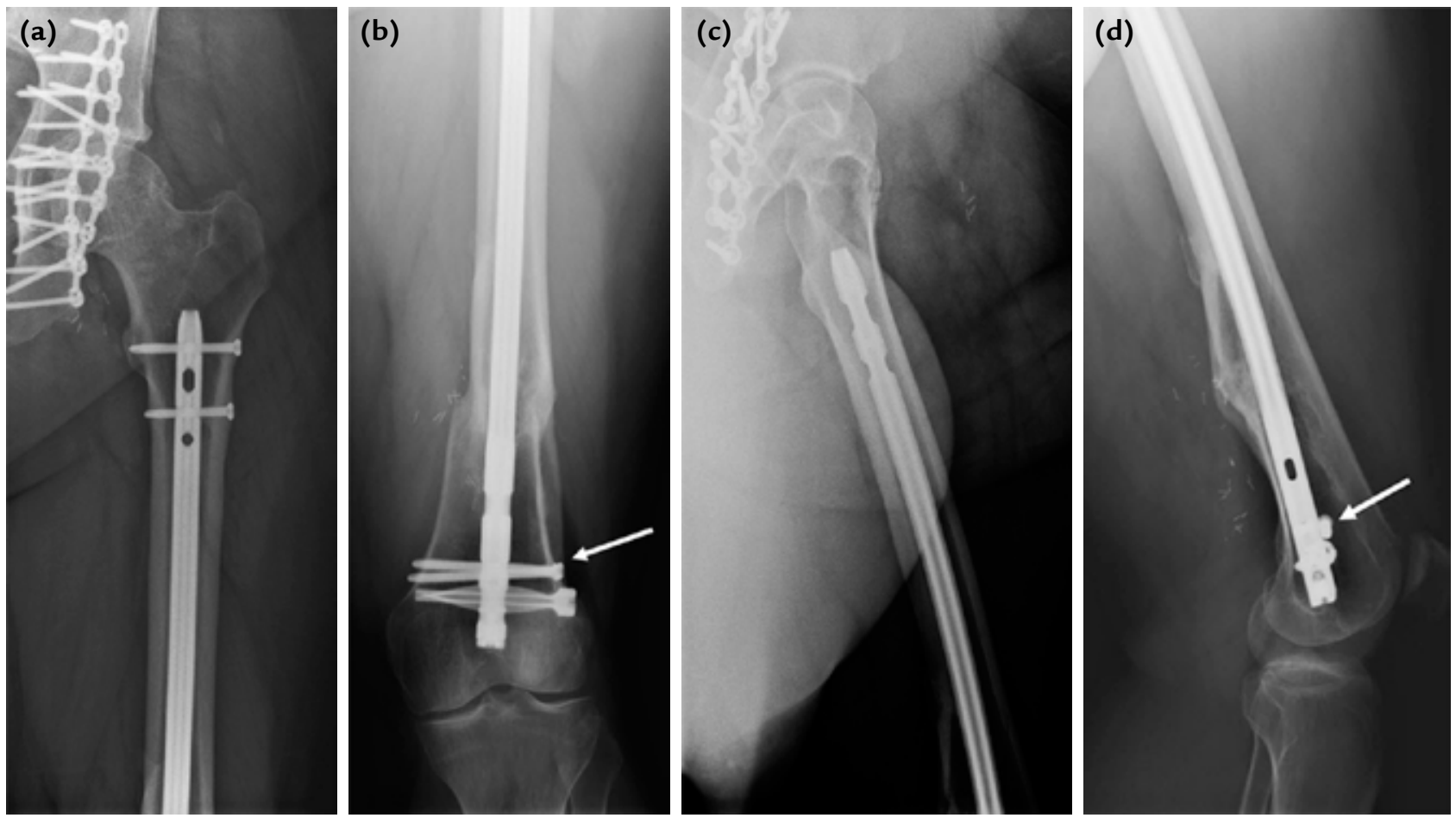

Şekil 8. a-d. Kırık iyileşmesi tamamlandıktan sonraki grafilerde bloklama vidası işaretlenmiş.

Kullanılacak çivi son oyucudan 1,0 veya $1,5 \mathrm{~mm}$ düşük çapta olmalıdır.

Kullanılacak çivi boyuna ameliyat öncesi sağlam taraftan yapılan ölçümlerle karar verilememişse, metal cetvel ile troklear çentik tepe noktası ile trokanter minör üst seviyesi arası ölçülerek çivi uzunluğu saptanabilir. Yahut, topuzlu ucu trokanter minör üst seviyesine getirilen içerideki kılavuz tel ile topuzlu ucu troklear çentiğe dayanan eş boyda bir başka telin arka uçları arasındaki uzunluk çivi boyu olarak belirlenebilir. ${ }^{[14]}$

Uzunluğu ve kalınlığı belirlenmiş çivi, kılavuz tel üzerinden hafif içe-dışa çevirme ve itme hareketleri ile dikkatli bir şekilde ilerletilir. Gerektiğinde arkadan nazik çekiç darbeleri vurulur. Çivinin kırık bölgesinden geçişi skopi ile izlenmeli, kırık diziliminin bozulmamasına özen gösterilmelidir. Proksimal uç tokanter minör üst seviyesinde, distal uç ise interkondiler çentikte eklem seviyesinden birkaç milimetre içerde subkondral seviyede olmalıdır. Yan görüntülemede çivinin Blumensaat çizgisi tepe noktasından biraz proksimalde olduğu kontrol edilmelidir. Çivi distal ucu fazla gömülü kalmışsa, ameliyat sonunda distal uca takılacak sonlandırma tıpası bunu telafi edecek uzunlukta seçilmelidir. Çivinin eklem içine taşar durumda kalması ise önemli bir sorundur ve düzeltilmelidir. ${ }^{[14]}$

\section{Distal Kilitleme}

Retrograd çivilemede önce distal kilitleme yapılır. Dışarıdan yönlendiriciler yardımı ile distal kilit vidaları veya spiral kama kolayca yerleştirilir. Kısa ve geniş distal parçada intramedüller çivinin içeriden kavrayıcı etkisi diyafiz bölgesindeki gibi güçlü olamayacağından, stabiliteyi arttırmak için distal kilitleme en az iki veya tercihen üç kilit vidasıyla ve birden fazla düzlemde yapılmalıdır. ${ }^{[12,19,20]}$ Özellikle osteoporotik kırıklarda önerilen spiral kamalı tasarımlarda, birden fazla düzlemde sağladıkları güçlü stabilite nedeniyle spiral kamaya bir distal kilit vidası ilavesi yeterli olmaktadır.

Distal kilit vidaları ikinci korteksi de geçmeli ama aşırı uzun olmamalıdır. Skopi ile oblik görüntüler alarak vidaların gerçek uzunluklarından emin olunmalıdır. Proksimal kilitlemeye geçmeden önce uzunluk ve rotasyon tekrar kontrol edilmelidir. Eğer kısalık var ise önce elle traksiyon denenmeli, uzunluk sağlanamıyorsa çivi çıkarma aleti üzerinden çivi ters yöne dikkatli bir şekilde çakılarak distraksiyon sağlanmaya çalışımalıdır.

\section{Proksimal Kilitleme}

Proksimal kilitleme, genellikle ön-arka yönde serbest el tekniği ile yapılır. Distal kilitleme deliği, tam 

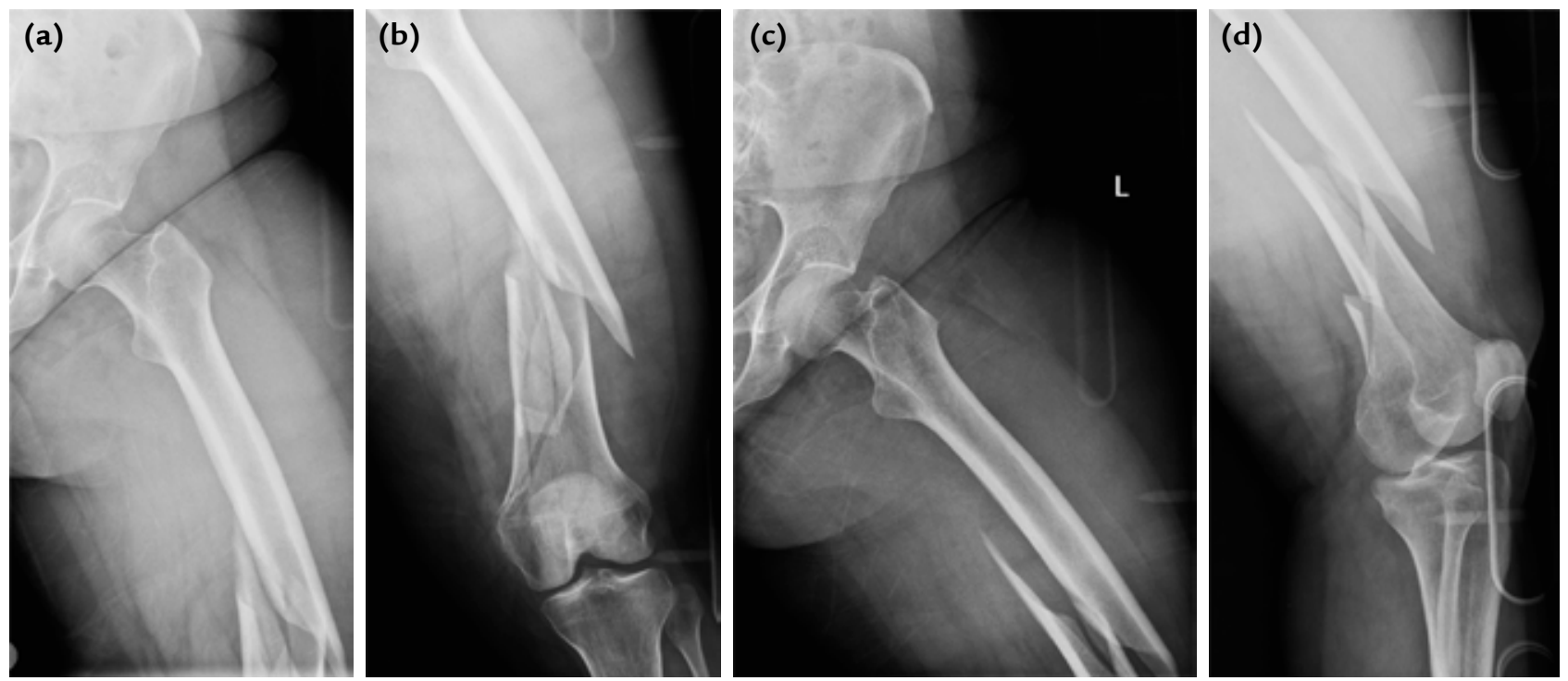

Şekil 9. a-d. Düşme sonucu distal femur kırı̆̆ı olan 56 yaşında kadın hastanın femur grafileri.
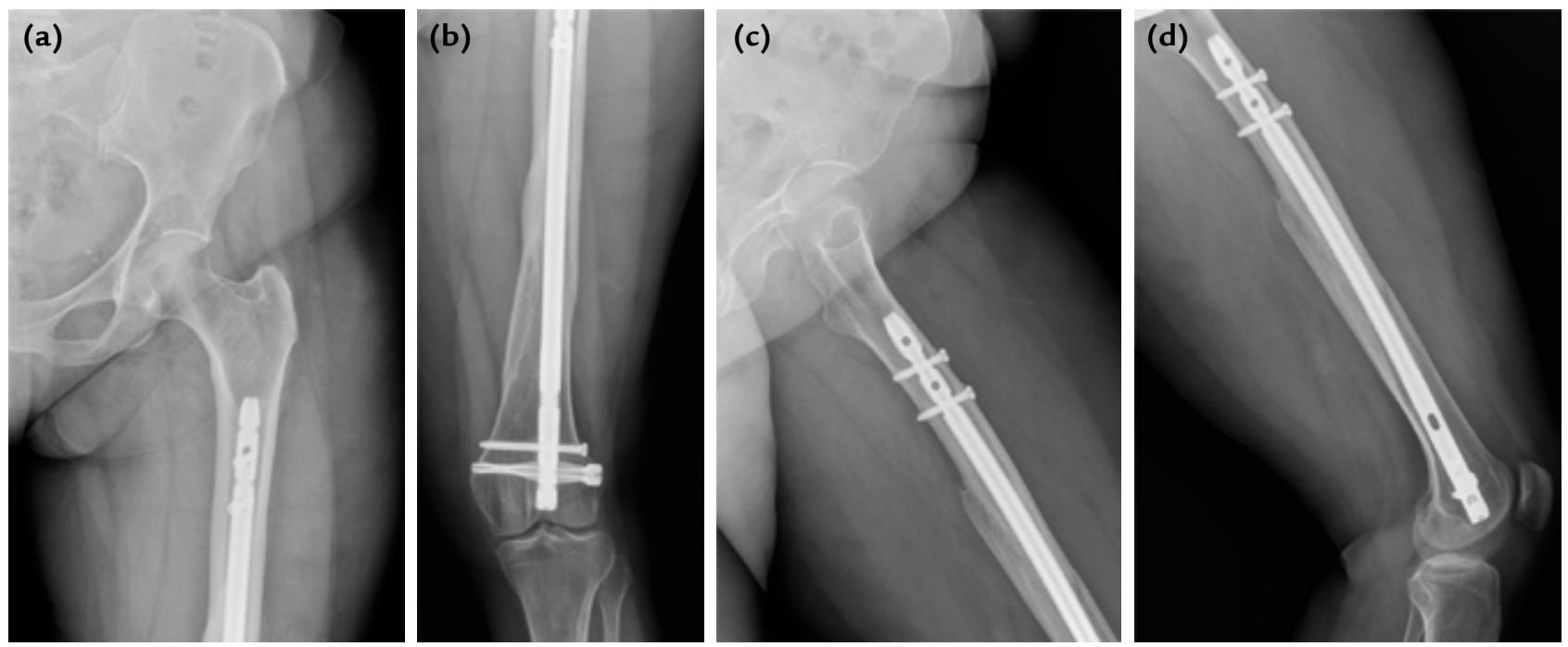

Şekil 10. a-d. Kapalı retrograd intramedüller çivileme uygulanan ve kırık iyileşmesi tamamlanmış olan olguda, distal kilitleme spiral kama ve ilave bir kilit vidası ile, proksimal kilitleme anteriordan posteriora iki kilit vidası ile yapılmış.

daire olacak şekilde görüntülenmelidir. Cilt insizyonu yapıldıktan sonra künt disseksiyonla femura ulaşılır. Bu bölgede femur korteksi sert olduğundan, sivri bir delici ile skopi görüntüsündeki dairenin tam ortasından giriş noktası hazırlandıktan sonra drill ile devam edilmesi kolaylık sağlar. Lateralden mediyale kilitleme opsiyonu da vardır. Ancak, skopi görüntülemesinin daha zor ve mediyale doğru fazla ilerlenirse femoral arterin yaralanma riskinin olduğu unutulmamalıdır. Delik açıldıktan sonra vida takılır. Vidanın yumuşak dokular arasında kaybolmaması için, vidanın proksimal ucuna sütür ipi bağlanıp gerektiğinde vidayı geri çıkarmakta kullanılabilir. Çoğu kırıkta tek proksimal kilit vidası yeterli görülürken, proksimale uzanan parçalı kırıklarda ikinci bir kilit vidası takılmalıdır. ${ }^{[14]}$ Şekil 9 ve 10'da kapalı retrograd intramedüller çivileme ile tedavi edilen bir distal femur kırığı olgusu gösterilmiştir.

Hasta uyandırılmadan önce sterilite bozularak, ameliyat edilen taraf sağlam taraf ile karşılaştırılarak muayene edilir. Belirgin bir uzunluk veya rotasyon farkı saptanırsa hasta tekrar steril olarak hazırlanır ve proksimal kilit vidalarının yeri değiştirilerek sorun düzeltilir. 


\section{KAYNAKLAR}

1. Chen CM, Chiu FY, Lo WH, Chuang TY. Ipsilateral hip and distal femoral fractures. Injury 2000;31(3):147-51. Crossref

2. Tornetta P 3rd, Kain MSH, Creevy WR. Diagnosis of femoral neck fractures in patients with a femoral shaft fracture. Improvement with a standard protocol. J Bone Joint Surg Am 2007;89(1):39-43. Crossref

3. Zlowodzki M, Bhandari M, Marek DJ, Cole PA, Kregor PJ. Operative treatment of acute distal femur fractures: systematic review of 2 comparative studies and 45 case series (1989 to 2005). J Orthop Trauma 2006;20(5):366-71. Crossref

4. Ostrum RF, Maurer JP. Distal third femur fractures treated with retrograde femoral nailing and blocking screws. J Orthop Trauma 2009;23(9):681-4. Crossref

5. Sanders R, Koval KJ, DiPasquale T, Helfet DL, Frankle M. Retrograde reamed femoral nailing. Orthop Trauma 1993;7(4):293-302. Crossref

6. Heiney JP, Barnett MD, Vrabec GA, Schoenfeld AJ, Baji A, Njus $G O$. Distal femoral fixation: a biomechanical comparison of trigen retrograde intramedullary (i.m.) nail, dynamic condylar screw (DCS), and locking compression plate (LCP) condylar plate. J Trauma 2009;66(2):443-9. Crossref

7. Janzing HM, Stockman B, Van Damme G, Rommens P, Broos PL. The retrograde intramedullary supracondylar nail: an alternative in the treatment of distal femoral fractures in the elderly? Arch Orthop Trauma Surg 1998;118(1-2):92-5. Crossref

8. Zlowodzki M, Williamson S, Cole PA, Zardiackas LD, Kregor PJ. Biomechanical evaluation of the less invasive stabilization system, angled blade plate, and retrograde intramedullary nail for the internal fixation of distal femur fractures. J Orthop Trauma 2004;18(8):494-502. Crossref

9. Krettek C, Miclau T, Schandelmaier P, Stephan C, Möhlmann $U$, Tscherne $H$. The mechanical effect of blocking screws ("Poller screws") in stabilizing tibia fractures with short proximal or distal fragments after insertion of small-diameter intramedullary nails. J Orthop Trauma 1999;13(8):550-3. Crossref
10. Ostrum RF, Agarwal A, Lakatos R, Poka A. Prospective comparison of retrograde and antegrade femoral intramedullary nailing. J Orthop Trauma 2000;14(7):496-501. Crossref

11. Ricci WM, Bellabarba C, Evanoff B, Herscovici D, DiPasquale $\mathrm{T}$, Sanders R. Retrograde versus antegrade nailing of femoral shaft fractures. J Orthop Trauma 2001;15(3):161-9. Crossref

12. Stedtfeld HW, Mittlmeier T, Landgraf $P$, Ewert A. The logic and clinical applications of blocking screws. J Bone Joint Surg Am 2004;86-A(Suppl 2):17-25. Crossref

13. O'Brien PJ, Meek RN, Blachut PA, Broekhuyse HM. Fractures of the distal femur. In: Bucholz RW, Heckman JD, editors. Rockwood and Green's Fractures in Adults. Philadelphia: Lippincott Williams \& Wilkins; 2001. p.1731-73.

14. Phieffer LS, Lakatos R. Retrograde intramedullary nailing of the femur. In: Wiesel SW, editor. Operative Techniques in Orthopaedic Trauma Surgery. Philadelphia: Wolters Kluwer/ Lippincott Williams \& Wilkins; 2011. p.370-81.

15. Barquet A. Distal femoral fracture. In: Robinson CM, Alho A, Court-Brown CM, editors. Musculoskeletal trauma series -femur. London: Arnold Publishers; 2002. p.128-43.

16. Ricci WM, Sanders R. Retrograd nailing of femoral shaft fractures. In: Robinson CM, Alho A, Court-Brown CM, editors. Musculoskeletal trauma series -femur. London: Arnold Publishers; 2002. p.112-27.

17. Krettek C, Stephan C, Schandelmaier P, Richter M, Pape HC, Miclau T. The use of Poller screws as blocking screws in stabilising tibial fractures treated with small diameter intramedullary nails. J Bone Joint Surg Br 1999;81-B(6):9638. Crossref

18. Seyhan M, Cakmak S, Donmez F, Gereli A. Blocking screws for the treatment of distal femur fractures. Orthopedics 2013;36(7):e936-41. Crossref

19. Chen SH, Yu TC, Chang CH, Lu YC. Biomechanical analysis of retrograde intramedullary nail fixation in distal femoral fractures. Knee 2008;15(5):384-9. Crossref

20. Kim JW, Oh CW, Kyung HS, Min WK, Yoon SH. Factors affecting the results of distal femoral fractures treated by retrograde intramedullary nailing. Zhongguo Xiu Fu Chong Jian Wai Ke Za Zhi 2009;23(11):1311-5. 